\title{
Eye - Tracking Could Contribute to The Diagnostics of The Can Syndrome
}

\author{
Jiri Jost, Helena Havlisova, Zuzana Bilkova, Olga Malinovska* and Zuzana Stefankova \\ Department of Psychology and Special Education, University of South Bohemia, Czech Republic
}

*Corresponding author: Olga Malinovska, Department of Psychology and Special Education, Faculty of Education, University of South Bohemia, Czech Republic.

To Cite This Article: SOlga Malinovska, Eye - Tracking Could Contribute to The Diagnostics of The Can Syndrome. Am J Biomed Sci \& Res. 2019 6(5). AJBSR.MS.ID.001073. DOI: 10.34297/AJBSR.2019.06.001073.

Received: 鮆 December 12,2019; Published: 盋 December 17, 2019

\begin{abstract}
Child abuse and neglect (CAN) has a range of negative outcomes. Its diagnostics is difficult. This paper deals with the diagnostic use of eyetracking. The authors see its potential in objectifying neuropsychiatric findings and in screening of the child population, where it could show with enough reliability to children at risk of CAN.
\end{abstract}

Keywords: Eye movements; Maltreatment; Abuse; Neglect; Antisaccade

Abbreviations: CAN: Child Abuse and Neglect

\section{Introduction}

CAN (Child Abuse and Neglect) is a multi-dimensional construct including [1] abuse or acts of commission, i.e. physical abuse, emotional abuse, and sexual abuse and [2] neglect or acts of omission, i.e. failure to meet a child's basic physical, emotional, medical/dental or educational needs [1]. Child maltreatment is the leading cause of children's referral to social services. Each child affecting by maltreatment is at risk for a range of negative outcomes, including chronic episodes of depression or elevated symptoms of anxiety [2], callous/unemotional traits as well as risk for violent behaviors to self and others [3], frequent occurrence of criminal outcomes in adult victims of child maltreatment [4], increased alcohol and substance use [5], risky sexual behavior and higher rates of teenage pregnancy [6], lower social competence and empathy [7], increased risk of lower levels of cognitive functioning and educational achievement [8], suicidality [9], problems in intimate partnership and risk for adulthood intimate partner violence [10], significantly impaired self-reported health related quality of life covering the physical, social and psychological aspects of health [11], increased risk of intergenerational transmission of child maltreatment [12].

The current diagnostic process of CAN syndrome depends on the observation of the child's development which includes the assessment of his/her family environment, a comparison of the views of people who come into regular contact with the child and his/ her family (kindergarten, primary school teachers, pediatricians, neighbors in the place of residence), and finally special examinations in health and school workplaces (child psychiatry, child neurology, child psychology). The diagnostic process is time-consuming, inter alia because of the lack of psychobiological markers which would contribute to the objectification of the finding. For example, if we ask an abused and neglected child "Who do you like most in the world?" we will obtain an answer that is comparable to a healthy child: "parents". A maltreated child is solving his/her problem by deeply unconscious defense mechanisms, e.g. by escaping to an imaginary world where everyone loves each other.

\section{Eye Movements and Their Potential Contribution for Diagnosis of Can Syndrome}

One of the possible solutions to this diagnostic problem may be the eye-tracking technology. The brain networks, which are the substrates of mental functions, are interconnected with networks that control eye movements [13]. Eye movements thus enter a relation with mental activity. With a literary license we may say that "the eye is the window to the soul." Poor emotional experiences shape the brain of an individual who is highly plastic 
in childhood. Schore assumes a significant structural defect of the orbitofrontal cortex which is responsible for self-regulation and contradictions to the social and emotional problems of individuals [14]. Similar arguments are presented for example in other studies [15-17]. Therefore, in eye movements and in the oculomotor test, we see a potential marker and method that can contribute to the objectification of CAN syndrome diagnosis. In contrast to neuroimaging methods, a method based on the recording of ocular micro-movements offers the subjects a natural environment to which they are accustomed, such as watching a television screen. The examination is accordingly completely non-invasive. However, there have probably only been a few attempts to find markers of CAN syndrome in eye movements. We are only aware of two studies: $[18,19]$. Both studies have identified issues that need to be addressed:

a. Will it be possible to find significant differences in the oculomotor test between children with CAN vs. children typically developing at an even younger age (pre-school age, early adolescence)? Mueller et al. [18] and Jost et al. [19] tested individuals with average age of 11 years and of 17 years, respectively.

b. What role does the degree of maltreatment have, as well as the time the child has been exposed to unfavorable influence? Jost et al. [19] have limited their study subjects to a severe degree with fully developed symptoms of psychosocial maladaptation, including criminal behavior. The subjects were exposed to this strain throughout their childhood. Mueller et al. [18] examined children with a milder grade and the deprivation period was relatively short - compared to the study by Jost et al.

c. What role does the individual's personality play in maltreatment and his/her resilience? Clinical practice suggests that some individuals are more prone while others are more resistant to the same adverse conditions.

d. What role does the sex play in deprivation? When exposed to maltreatment, girls tend to be more resistant - as observed by the so-called Prague study [12].

e. What role do different types of eye movements play? The authors of the previously presented studies $[18,19]$ worked with saccades and antisaccades. How will the oculomotor image change when we use different tasks?

f. Differential diagnostics problem. The antisaccadic test, also applied in Mueller et al. [18] and Jost et al. studies [19], is sensitive to frontal dysfunction, which is the basis for several syndromes [20]. Therefore, the antisaccadic test may not be a good differential diagnostic tool capable of distinguishing one syndrome from another. The sensitivity of the antisaccadic test is probably also age-related. Biscaldi, Fischer \& Hartnegg [21] found significant differences between the dyslexics and the controls beginning approximately at the age of 10 years. At the age of 8 years, however, the authors were not able to differentiate between the two groups using the antisaccadic test.

\section{Conclusion}

Eye-tracking technology could be a way to solve the presented problem. It is undemanding in terms of personnel and time and offers high comfort for the investigated subject. We see its potential [1] in screening the child population where it could show with sufficient reliability the children at risk for CAN syndrome and [2] as part of a neuropsychiatric, pedopsychological or special educational examination to help formulate a diagnostic hypothesis and orientate the next diagnostic procedures.

\section{References}

1. Child Welfare Information Gateway (2013). What is child abuse and neglect? Recognizing the signs and symptoms. Factsheets Washington (USA).

2. Infurna MR, Reichl C, Parzer P, Schimmenti A, Bifulco A, et al. (2016) Associations between depression and specific childhood experiences of abuse and neglect: A meta-analysis. J Affect Disord 190: 47-55.

3. Carlson M, Oshri A, Kwon J (2015) Child maltreatment and risk behaviors: The roles of callous/unemotional traits and conscientiousness. Child Abuse Negl 50: 234-243.

4. Keene AC, Epps J (2016) Childhood physical abuse and aggression: Shame and narcissistic vulnerability. Child Abuse Negl 51: 276-283.

5. Shin SH, Lee S, Jeon SM, Wills TA (2015) Childhood emotional abuse, negative emotion-driven impulsivity, and alcohol use in young adulthood. Child Abuse Negl 50: 94-103.

6. Vinnerljung B, Sallnäs M (2008) Into adulthood: A follow-up study of 718 young people who were placed in out-of-home care during their teens. Child \& Family Social Work 13(2): 144-155.

7. Hocking EC, Simons RM, Surette RJ (2016) Attachment style as a mediator between childhood maltreatment and the experience of betrayal trauma as an adult. Child Abuse Negl 52: 94-101.

8. Maclean MJ, Taylor CL, O’Donnell M (2016) Pre-existing adversity, level of child protection involvement, and school attendance predict educational outcomes in a longitudinal study. Child Abuse Negl 51: 120-131.

9. Taussig HN, Harpin SB, Maguire SA (2014) Suicidality among preadolescent maltreated children in foster care. Child Maltreat 19(1): 17-26.

10. Hocking EC, Simons RM, Surette RJ (2016) Attachment style as a mediator between childhood maltreatment and the experience of betrayal trauma as an adult. Child Abuse Negl 52: 94-101.

11. Jud A, Landolt MA, Tatalias A, Lach LM, Lips U (2013) Health-related quality of life in the aftermath of child maltreatment: follow-up study of a hospital sample. Qual Life Res 22(6): 1361-1369.

12. Kubicka L, Roth Z, Dytrych Z, Matejcek Z, David HP (2002) The mental health of adults born of unwanted pregnancies, their siblings, and matched controls: a 35-year follow-up study from Prague, Czech Republic. J Nerv Ment Dis 190(10): 653-662.

13. Rommelse NJ, Van der Stigchel S, Sergeant JA (2008) A review on eye movement studies in childhood and adolescent psychiatry. Brain Cogn 68(3): 391-414.

14. Schore AN (2009) Relational Trauma and the Developing Right Brain: An Interface of Psychoanalytic Self Psychology and Neuroscience. Ann NY Acad Sci 1159: 189-203. 
15. Bick J, Fox N, Zeanah C, Nelson CA (2017) Early deprivation, atypica brain development, and internalizing symptoms in late childhood. Neuroscience 342: 140-153.

16. Bick J, Zhu T, Stamoulis C, Fox NA, Zeanah C, et al. (2015) A Randomized Clinical Trial of Foster Care as an Intervention for Early Institutionalization: Long Term Improvements in White Matter Microstructure. JAMA Pediatr 169(3): 211-219.

17. Kolb B, Mychasiuk R, Muhammad A, Li Y, Frost DO, et al. (2012) Experience and the developing prefrontal cortex. Proc Natl Acad Sci USA 109(Suppl 2): 17186-17193.

18. Mueller SC, Hardin MG, Korelitz K, Daniele T, Bemis J, et al. (2012) Incentive effect on inhibitory control in adolescents with early-life stress: An antisaccade study. Child Abuse Negl 36(3): 217-225.
19. Jost J, Havlisova H, Stefankova Z, Zemkova L, Zuzana Bilkova (2018) Adolescents with persistent history of maltreatment fail in antisaccadic task. Journal of Child \& Adolescent Trauma 11(2): 163-171.

20. Leigh RJ, Zee DS (2015) The neurology of eye movements ( $5^{\text {th }}$ edn), Oxford University Press (USA), New York, USA.

21. Biscaldi M, Fischer B, Hartnegg K (2000) Voluntary saccadic control in dyslexia. Perception 29(5): 509-521. 